\title{
Monitoramento do desempenho da técnica de reciclagem profunda em pavimentos do estado de Goiás
}

\section{Rafaella Oliveira Guimarães Santos ${ }^{1}$, Lilian Ribeiro de Rezende ${ }^{2}$, Valdemar Martins da Silva Junior $^{3}$, Ludmila Cabrine Silva Costa ${ }^{4}$, Jorge Hernán García Hómez ${ }^{5 凶}$}

${ }^{1}$ Centro Universitário de Goiás Uni-Anhanguera, rafaellaguimaraes.eng.@gmail.com

2Universidade Federal de Goiás, PPG em Geotenica, Estruturas e Construção Civil, rezende.lilian@gmail.com

${ }^{3}$ Universidade Federal de Goiás, PPG em Geotenica, Estruturas e Construção Civil, valdemarjr11@gmail.com

${ }^{4}$ Departamento Nacional de Insfraestrutura de Transporte, lud.cabrine@gmail.com

5Universidade Federal de Goiás, PPG em Geotenica, Estruturas e Construção Civil, jorge_hernan_garcia@hotmail.com

\section{Recebido:}

05 de setembro de 2016

Aceito para publicação:

07 de agosto de 2017

Publicado:

30 de dezembro de 2017

Editor de área:

Jorge Barbosa Soares

\section{Palavras-chaves:}

Pavimento asfáltico,

Restauração,

Monitoramento funcional e

estrutural,

Módulo de resiliência,

Retroanálise.

\section{Keywords:}

Asphalt pavement,

Rehabilitation,

Functional and structural pavement

monitoring,

Resilient modulus,

Backanalysis.

DOI:10.14295/transportes.v25i4.1244

\begin{abstract}
RESUMO
Este estudo avaliou três rodovias que adotaram a reciclagem profunda com acréscimo de materiais como solução para reconstrução da base. Foi realizada uma comparação de resultados obtidos com ensaios executados em duas fases. Na primeira, foi feita a coleta de material de base para caracterização em laboratório e a realização de ensaios de campo logo após a abertura ao tráfego, complementando com a retroanálise dos dados. Na segunda, repetiu-se os ensaios de campo, a retroanálise e extraiu-se amostras do revestimento para novas análises. Algumas características das misturas não atenderam valores normatizados. Entretanto, os resultados mecânicos foram satisfatórios. As soluções adotadas para as rodovias avaliadas demonstraram potencial de utilização desde que sejam realizados estudos laboratoriais adequados e controle tecnológico durante a execução.
\end{abstract}

\section{ABSTRACT}

This study evaluated three highways that were rehabilitated deep reclaimed asphalt. The first evaluation was performed by collecting base material for laboratory tests and doing field tests and back calculation after the opening to traffic. The results obtained previously were compared with a second evaluation years later). Additional laboratory tests determined data from extracted surface course samples. Some characteristics of the mixtures did not attempt standard values. However, the mechanical results were satisfactory. The solutions adopted for highways demonstrated potential of use, but correct laboratory tests and technological control have to be done.

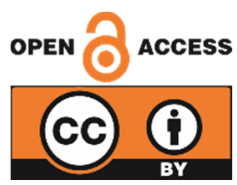

\section{INTRODUÇÃO}

0 transporte rodoviário detém a maior participação na matriz do transporte de cargas no Brasil (CNT, 2015). Para a manutenção das rodovias, os processos de restauração devem ser periódicos e, geralmente, contemplam aplicação de novas camadas de revestimento asfáltico, retirando ou não a camada 
defeituosa (ARRA, 2001), apresentando-se como solução viável. Dentre os tipos de reciclagem existentes, a profunda é um serviço que pode gerar: aumento da resistência estrutural, melhor condição de conforto, segurança e maior vida útil (Morian et al., 2012). Esse tipo de construção é selecionado em função da condição estrutural e funcional do pavimento existente, da disponibilidade de materiais, da demanda de tráfego e do custo. Nessa técnica, o acréscimo de materiais como brita, cascalho e cimento, pode ser necessário para melhorar a qualidade da base estabilizada. Estudos têm sido desenvolvidos para verificar a possibilidade de aplicação desses materiais em substituição aos convencionais (Park, 2007; Sachet, 2007; Silva, 2011; Jaritngam et al., 2012; Rosa et al., 2015).

As principais vantagens e benefícios da reciclagem profunda são (FHWA, 1997):

- Melhoria significativa da estrutura, sem alterar a geometria do pavimento;

- Adequação do pavimento antigo para o perfil desejado, eliminando-se afundamentos, buracos, irregularidades, áreas acidentadas e trincas;

- Redução do custo de produção;

- Conservação de materiais e energia, minimizando problemas de qualidade do ar resultante da poeira, fumos e fumaça, e de disposição de resíduos.

FHWA (1997) complementa que antes de iniciar a construção, é muito importante saber a qualidade do pavimento existente em termos de composição e situação atual. Uma vez que os segmentos são identificados, amostras representativas devem ser coletadas. Dessa maneira, a variabilidade do material existente pode ser identificada e avaliada.

Bessa et al. (2016) observaram a viabilidade da reciclagem profunda com adição de cimento em um trecho da BR-381, onde a base foi reconstruída com uma espessura de $30 \mathrm{~cm}$ e apresentou desempenho aceitável em campo para a compactação na energia modificada e o teor de cimento de $5 \%$. Para otimizar a quantidade do agente estabilizante e as propriedades físicas da mistura reciclada, deve ser realizado um estudo preliminar em laboratório. 0 projeto serve como referência, mas devem ser realizados ajustes de campo com base no controle de qualidade da mistura reciclada (ARRA, 2001). Assim, a reciclagem profunda pode ser uma ferramenta de baixo custo para melhoramento das rodovias, desde que seja feito o controle adequado durante a execução. No Brasil, não há alguma organização governamental ou não voltada especificamente para reciclagem de pavimentos asfálticos, mas a temática é comumente abordada dentro das empresas e órgãos rodoviários. 0 elevado número de variáveis associadas à reciclagem, especialmente devido à variabilidade do material deteriorado, justifica a dificuldade de fixação de procedimentos totalmente aceitos (Silva, 2011).

Além dessa falta de padronização dos serviços de reciclagem, em Goiás ainda há ausência de estudos avançados sobre misturas asfálticas. Os dados obtidos, geralmente, são apresentados e controlados somente pelas empresas que produzem a massa e a fiscalização pouco avalia parâmetros do material entregue na obra. Os ensaios realizados ainda são baseados na metodologia Marshall e não preveem o comportamento da mistura utilizada quando submetida ao carregamento dinâmico e à variação de temperatura (Prudente, 2015). Sendo assim, as duas situações podem gerar redução na durabilidade das obras de restauração executadas na região. De acordo com Chen e Xu (2009), tanto a temperatura quanto o carregamento têm efeitos significativos no desempenho da mistura a quente, obtendo maiores deformações quanto maior a carga e mais alta a temperatura. Segundo Medina e Motta (2015), nas regiões tropicais pode-se atribuir ao revestimento asfáltico, quando não dosado convenientemente, a maior contribuição na deformação permanente do que às camadas de bases e sub-bases. Essas podem apresentar deformações por densificação adicional pelo tráfego e por ruptura ao cisalhamento. No Brasil, pesquisas demonstram que misturas asfálticas dosadas pelo Superpave resultam em teor de ligante menor do que aquelas dosadas pela Marshall (Marques, 2004; Vasconcelos, 2004; Ibrahim, 2007; Prowell e Brown, 2007).

Nesse contexto, o objetivo deste artigo é avaliar o comportamento de três rodovias de pavimentos asfálticos que foram restauradas por meio da técnica de reciclagem profunda com acréscimo de materiais como solução para reconstrução da base e com a execução de uma nova capa asfáltica. 


\section{METODOLOGIA}

Esta pesquisa abrange o monitoramento de trechos de três rodovias restauradas com reciclagem profunda da base e execução de uma nova camada de concreto asfáltico como revestimento. São elas: GO222, GO-215 e GO-147. As soluções adotadas para a restauração, o trecho e o tipo de revestimento são observadas na Tabela 1. Destaca-se que não foi realizado e nem contratado o estudo de tráfego pelo órgão responsável (Agência Goiana de Transportes e Obras, AGETOP). Portanto, não foi possível determinar o número de solicitações de eixo padrão $(\mathrm{N})$ na época da restauração das vias e, consequentemente, do tráfego atual e futuro das mesmas.

Tabela 1: Informações sobre as rodovias

\begin{tabular}{|c|c|c|c|c|c|c|c|}
\hline \multirow{2}{*}{ Rodovia } & \multirow{2}{*}{$1^{\text {a }}$ Avaliação } & \multirow{2}{*}{$\begin{array}{c}\text { Extensão } \\
(\mathrm{km})\end{array}$} & \multirow{2}{*}{ Trecho } & \multirow{2}{*}{ Base antiga } & \multicolumn{2}{|c|}{ Solução para a base } & \multirow{2}{*}{$\begin{array}{c}\text { Tipo de } \\
\text { Revestimento }\end{array}$} \\
\hline & & & & & Projeto & Executada & \\
\hline GO-222 & $\begin{array}{c}2012 \\
\text { (Costa, } \\
2013)\end{array}$ & 8 & $\begin{array}{l}\text { Anápolis / } \\
\text { Nerópolis }\end{array}$ & $\begin{array}{l}\text { Cascalho } \\
\text { laterítico }\end{array}$ & $\begin{array}{l}\text { RB com adição de } \\
3 \% \text { de cimento e } \\
\text { incorporação de } 8 \\
\text { cm de cascalho } \\
\text { novo. Espessura fi- } \\
\text { nal da base } 15 \mathrm{~cm} \text {. }\end{array}$ & 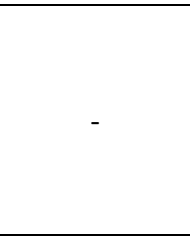 & $\begin{array}{c}\text { CA } \\
\text { (3 a } 4 \mathrm{~cm} \mathrm{de} \\
\text { espessura) }\end{array}$ \\
\hline GO-215 & $\begin{array}{c}2014 \\
\text { (Hómez, } \\
\text { 2014) }\end{array}$ & 8 & $\begin{array}{l}\text { Edéia / } \\
\text { Pontalina }\end{array}$ & $\begin{array}{l}\text { Cascalho } \\
\text { laterítico }\end{array}$ & $\begin{array}{l}\text { RB com adição de } \\
\text { até } 25 \% \text { de } \\
\text { brita.Espessura fi- } \\
\text { nal da base de } \\
18 \mathrm{~cm} .\end{array}$ & $\begin{array}{c}\text { RB com } \\
\text { adição de } \\
12 \% \text { de brita }\end{array}$ & $\begin{array}{c}\text { CA } \\
(4 \mathrm{~cm} \text { de espessura) }\end{array}$ \\
\hline GO-147 & $\begin{array}{c}2014 \\
\text { (Rezende, } \\
\text { 2014) }\end{array}$ & 8 & $\begin{array}{c}\text { GO-020 / } \\
\text { Piracanjuba }\end{array}$ & $\begin{array}{l}\text { Cascalho } \\
\text { laterítico }\end{array}$ & $\begin{array}{l}\text { RB com adição de } \\
\text { até } 25 \% \text { de } \\
\text { brita.Espessura fi- } \\
\text { nal da base } 18 \mathrm{~cm}\end{array}$ & $\begin{array}{c}\text { RB com } \\
\text { adição de } 6 \% \\
\text { de brita }\end{array}$ & $\begin{array}{c}\mathrm{CA} \\
(4 \mathrm{~cm} \text { de espessura })\end{array}$ \\
\hline
\end{tabular}

Obs.: $\mathrm{RB}=$ reciclagem de base; $\mathrm{CA}=$ concreto asfáltico

A restauração da GO-222 foi executada em 2012, sendo definido em projeto que além do cimento, haveria a incorporação de mais cascalho. Para tanto foi adicionada uma camada de cascalho solto com 8 $\mathrm{cm}$ de espessura sobre o pavimento existente para então proceder a reciclagem. Inicialmente, foram realizados ensaios laboratoriais com amostras de materiais coletados durante a execução da obra. A primeira avaliação estrutural e funcional foi executada logo após a abertura da rodovia ao tráfego (Costa, 2013). As obras de restauração das GO-215 e GO-147 foram realizadas em 2013, sendo os ensaios de laboratório apresentados por Silva Junior (2015) e os de campo por Hómez (2014) e Rezende (2014). Nas duas rodovias, a solução de projeto previa a reciclagem de base com adição de $25 \%$ de brita e concreto asfáltico (CA) de $4 \mathrm{~cm}$. Entretanto, Silva Junior (2015) constatou que, na realidade, na GO-215 foi adicionado $12 \%$ de brita e na G0-147 apenas 6\%. Ressalta-se que em todos os casos o revestimento asfáltico fresado foi incorporado ao material de base.

Na Tabela 2, é apresentado o resumo dos resultados de caracterização, compactação, expansão, California Bearing Ratio (CBR) e triaxial dinâmico para os materiais das bases recicladas coletados nas pistas na época da execução das obras. Neste trabalho, manteve-se a metodologia usada em campo nas pesquisas anteriores (Costa, 2013; Hómez, 2014; Rezende, 2014), realizando os ensaios no mesmo trecho de 8 km após três anos de realização da obra da G0-222 e após um ano e meio nas GO-215 e G0-147.

Neste artigo, o foco dos ensaios de laboratório foi analisar parâmetros dos revestimentos. Para tanto, realizou-se a coleta de corpos de prova (CP) de CA com o auxílio da extratora. As dimensões dos CPs foram determinadas antes e depois do corte para separação da camada de imprimação. Os CPs foram utilizados para determinação da densidade aparente, massa específica máxima medida e teor de ligante. Após extração do teor de ligante, realizaram-se ensaios de granulometria e massa específica dos grãos. Para os ensaios de resistência à tração por compressão diametral (RT) e módulo de resiliência (MR), os CPs foram nivelados por meio de corte ou lixamento. Na GO-222, foram extraídos dez CPs, mas após a 
separação da camada de imprimação, nenhum deles apresentou altura de 3,5 cm para realização dos ensaios de RT e MR. Já os CPs extraídos das outras rodovias apresentaram altura suficiente para realização de todos os ensaios (Tabela 3), sendo que a variabilidade das dimensões obtidas foi pequena.

Tabela 2: Resumo dos resultados de caracterização, compactação, expansão e parâmetros mecânicos para os materiais das bases recicladas

\begin{tabular}{|c|c|c|c|}
\hline Parâmetros & GO-222 (Costa, 2013) & GO-215 (Silva Jr., 2015) & GO-147(Silva Jr., 2015) \\
\hline Pedregulho (\%) & 74,62 & 64,68 & 47,44 \\
\hline Areia (\%) & 15,41 & 24,42 & 34,40 \\
\hline Silte (\%) & 3,99 & 3,49 & 5,99 \\
\hline Argila (\%) & 5,98 & 7,41 & 12,17 \\
\hline$w_{L}(\%)$ & 32 & 26 & 31 \\
\hline$W_{P}(\%)$ & 24 & 17 & 21 \\
\hline $\operatorname{IP}(\%)$ & 8 & 9 & 10 \\
\hline Classificação TRB & A-2-4 & $A-2-4$ & A-2-4 \\
\hline Energia de compactação & Intermodificada & Modificada & Modificada \\
\hline$\gamma_{\mathrm{dmax}}\left(\mathrm{kN} / \mathrm{m}^{3}\right)$ & 22,00 & 22,8 & 21,5 \\
\hline$w_{\text {ot }}(\%)$ & 7,80 & 6,20 & 9,5 \\
\hline Expansão (\%) & 0,06 & 0,05 & 0,02 \\
\hline CBR $w_{\text {ot }}(\%)$ & 104 & 100 & 105 \\
\hline $\mathrm{MR}(\mathrm{MPa})$ & $\begin{array}{c}911\left(\sigma_{3}=0,14 \mathrm{MPa} \text { e }\right. \\
\left.\sigma_{\mathrm{d}}=0,28 \mathrm{MPa}\right)\end{array}$ & $\begin{array}{c}214\left(\sigma_{3}=0,02 \mathrm{MPa} \text { e }\right. \\
\left.\sigma_{\mathrm{d}}=0,24 \mathrm{MPa}\right)\end{array}$ & $\begin{array}{c}464\left(\sigma_{3}=0,02 \mathrm{MPa} \text { e }\right. \\
\left.\sigma_{\mathrm{d}}=0,24 \mathrm{MPa}\right)\end{array}$ \\
\hline
\end{tabular}

Obs.: $\mathrm{w}_{\mathrm{L}}=$ Limite de Liquidez; $\mathrm{w}_{\mathrm{P}}=$ Limite de Plasticidade; $\mathrm{IP}=$ Índice de Plasticidade; $\mathrm{TRB}=$ Transportation Research Board; $\gamma_{\mathrm{dmax}}=$ peso específico aparente seco máximo; $\mathrm{w}_{\mathrm{ot}}=$ umidade ótima; $\mathrm{CBR}=$ California Bearing Ratio; $\mathrm{MR}=$ Módulo de Resiliência.

Tabela 3: Dimensões dos CPs de CA

\begin{tabular}{cccccccccc}
\hline \multirow{2}{*}{ Rodovia } & \multicolumn{3}{c}{$\mathrm{H}_{0}$} & \multicolumn{3}{c}{$\mathrm{H}_{1}$} & \multicolumn{3}{c}{ D } \\
\cline { 2 - 10 } & Média $(\mathrm{mm})$ & DP & CV & Média $(\mathrm{mm})$ & DP & CV & Média $(\mathrm{mm})$ & DP & CV \\
\hline GO-222 & 34,59 & 4,42 & 0,128 & 27,82 & 4,33 & 0,156 & 99,98 & 0,40 & 0,004 \\
GO-215 & 41,05 & 4,17 & 0,101 & 36,45 & 4,42 & 0,121 & 99,91 & 0,48 & 0,005 \\
GO-147 & 47,48 & 5,86 & 0,123 & 39,08 & 0,14 & 0,137 & 100,15 & 0,44 & 0,004 \\
\hline
\end{tabular}

Obs.: $\mathrm{H}_{0}=$ altura antes do corte para separação da camada de imprimação; $\mathrm{H}_{1}=$ altura depois do corte; $\mathrm{D}=$ diâmetro, $\mathrm{DP}=$ desvio padrão, $\mathrm{CV}$ = coeficiente de variação.

Determinou-se a densidade aparente das amostras conforme a ME 117 (DNER, 1994a) e a massa específica máxima medida por meio do Rice Test (ASTM, 2011). 0 ensaio para definição do percentual do cimento asfáltico de petróleo (CAP) foi realizado conforme a ME 053 (DNER, 1994b). Após a extração do CAP, caracterizou-se o material de acordo com a ME 083 (DNER, 1998a). Para a determinação da massa específica dos agregados miúdos, utilizou-se a ME 084 (DNER, 1995). A quantidade de material para determinação da massa específica dos agregados graúdos não atendeu ao determinado pela ME 081(DNER, 1998b). Na presente pesquisa, teve-se acesso ao projeto original das misturas dos CAs utilizados nas rodovias G0-215 e G0-147, obtendo informações sobre agregados e dosagem definida na época da execução das obras. Esses dados foram utilizados para comparação e cálculo dos parâmetros de volumetria: densidade máxima teórica (DMT), volume de vazios (Vv), volume do agregado mineral (VAM) e relação betume vazios (RBV). De acordo com informações fornecidas pelas empresas, as misturas asfálticas foram compostas pelos materiais apresentados na Tabela 4. Ressalta-se que no caso da GO222, por ser a mais antiga e uma das primeiras a serem restauradas com a técnica em estudo, não foi possível resgatar as informações originais sobre a mistura asfáltica utilizada.

Para avaliar os parâmetros mecânicos, realizaram-se ensaios para determinação da RT segundo a ME 136 (DNIT, 2010b). A RT aumenta com o envelhecimento das misturas na pista, tendo como desvantagem a perda de sua flexibilidade. Também foram executados ensaios para determinação da rigidez por compressão diametral sob carga repetida por meio da NBR 16018 (ABNT, 2011). Ponte et al. (2014) recomendam essa normativa para a realização de ensaios de MR no Brasil ao invés do uso da ME 135 (DNIT, 2010c), uma vez que a NBR 16018 forneceu resultados com menor sensibilidade no quesito repetibilidade quanto à mistura ensaiada pelos autores, como também menor dispersão dos resultados. 0 
ensaio de MR foi executado numa prensa hidráulica UTM-30. Os valores de tensão de tração aplicados foram da ordem de $10 \%$ da resistência à tração obtida no ensaio de RT. Na presente pesquisa, os ensaios foram realizados a $25^{\circ} \mathrm{C}$.

Tabela 4: Materiais constituintes das misturas conforme os projetos

\begin{tabular}{cccc}
\hline & Rodovia & GO-215 & GO-147 \\
\hline & Rocha de origem & Granito & Micaxisto \\
Faixa DNIT & C & C \\
& Brita 3/4" (\%) & 16,00 & 16,15 \\
Brita 3/8" (\%) & 29,20 & 36,10 \\
Agregados & Pó de pedra (\%) & 40,70 & 14,25 \\
& Areia (\%) & 7,50 & 28,50 \\
& Fíler (\%) & 0,90 & 0,00 \\
& Densidade real dos agregados $\left(\mathrm{g} / \mathrm{cm}^{3}\right)$ & 2,727 & 2,870 \\
\hline \multirow{3}{*}{ Ligante } & Tipo & AMP $60 / 85$ & CAP 50/70 \\
& Densidade $\left(\mathrm{g} / \mathrm{cm}^{3}\right)$ & 1,054 & 1,038 \\
& Teor de projeto $(\%)$ & 5,8 & 5,0 \\
\hline
\end{tabular}

Obs.: AMP = Asfalto Modificado por Polímero; CAP = Cimento Asfáltico de Petróleo

Foram realizados ensaios com a viga Benkelman para determinação das bacias de deslocamento. Ressalta-se que o Falling Weight Deflectometer (FWD) é mais moderno e apresenta resultados mais confiáveis. Entretanto, o uso desse equipamento foi inviabilizado por não estar disponível na região. A viga Benkelman, apesar de não ser um equipamento moderno, tem baixo custo e pode apresentar dados satisfatórios desde que os ensaios sejam bem executados e os dados sejam analisados adequadamente. No estudo em questão, em cada rodovia e em cada etapa, foram realizados cerca de 400 ensaios, com resultados tratados estatisticamente. Conforme especifica o ME 133 (DNIT, 2010a), os ensaios foram realizados de $100 \mathrm{~m}$ em $100 \mathrm{~m}$ de maneira alternada nas trilhas de roda externas nas duas faixas da via. A medida das deflexões máximas foi realizada de $20 \mathrm{~m}$ em $20 \mathrm{~m}$, também de maneira alternada entre as faixas. A calibração da viga foi realizada em laboratório, conforme o PRO 175 (DNER,1994c). Após as medições, a avaliação estrutural foi realizada segundo o PRO 011 (DNER, 1979), dividindo o trecho em segmentos homogêneos. Como o revestimento era do tipo CA, as deflexões foram padronizadas para uma temperatura, de acordo com a IP-DE-P00/003 (DER-SP, 2003). Para a avaliação funcional, foi realizado o levantamento das flechas nas trilhas de roda interna e externa com a treliça metálica e identificação dos defeitos segundo a PRO 006 (DNIT, 2003b). Foi efetuado também o levantamento da condição da superfície de acordo com a PRO 007 (DNIT, 2003c), focando no trincamento e no desgaste.

Também foram realizados ensaios com Dynamic Cone Penetration (DCP) conforme a D 6951 (ASTM, 2003). A escolha das estacas para realização dos ensaios ocorreu em função dos segmentos que já haviam sido estudados por Costa (2013), Hómez (2014) e Rezende (2014), alternando cada ensaio de 200 m em $200 \mathrm{~m}$ entre as faixas. Assim, foi possível determinar a espessura e a resistência à penetração de cada camada. Na GO-147 não foi possível realizar esse ensaio no ano de 2014.

A retroanálise foi realizada por meio de análises elástico-lineares com o programa Kenlayer (HUANG, 2004). Foram utilizados os dados obtidos nos ensaios de viga Benkelman e as bacias de deslocamento foram retroanalisadas para estimar o módulo de elasticidade. 0 programa faz a comparação de maneira iterativa entre as bacias medidas com as calculadas, até que haja semelhança. Já que a deflexão máxima $\left(D_{0}\right)$ é o principal parâmetro de análise do programa Kenlayer, como critério de semelhança entre as bacias reais e as encontradas, procurou-se, inicialmente, aproximar o primeiro ponto de ambas. Ao final do processo, a forma de toda a bacia foi avaliada. As cargas e pressão dos pneus foram usadas conforme padrões definidos para o ensaio (DNIT, 2010a). Os valores para coeficientes de Poisson utilizados foram de 0,45 para o subleito, 0,40 para base e sub-base e 0,30 para o revestimento (Macêdo, 2003; Ressutte et al., 2015). Os módulos necessários como parâmetros de entrada foram definidos com os resultados de MR para o revestimento e estimados para as camadas de base, sub-base e subleito. Já as espessuras e a quantidade de camadas foram definidas por meio do ensaio de DCP. 


\section{APRESENTAÇÃO E ANÁLISE DOS RESULTADOS}

\subsection{Ensaios de laboratório}

\subsubsection{Características das misturas asfálticas}

Na Figura 1 são apresentadas as curvas granulométricas dos materiais obtidas após a extração de betume, bem como as curvas considerando a tolerância máxima e mínima para atender aos requisitos para Faixa C da ES 031 (DNIT, 2006a). Percebe-se que o tamanho nominal máximo dos agregados para as três rodovias foi de 19,1 mm. Observa-se que para as GO-215 e GO-222, as curvas estão acima do limite superior determinado pela ES 031 (DNIT, 2006a), indicando a existência de finos. Na determinação da massa específica dos agregados miúdos, os materiais apresentaram valores de $2,793 \mathrm{~g} / \mathrm{cm}^{3}$ para a GO$222,2,712 \mathrm{~g} / \mathrm{cm}^{3}$ para a GO-215 e 2,706 g/ $\mathrm{cm}^{3}$ para a GO-147. Devido à impossibilidade de determinação da massa específica dos agregados graúdos, foram utilizados os valores fornecidos em projeto.

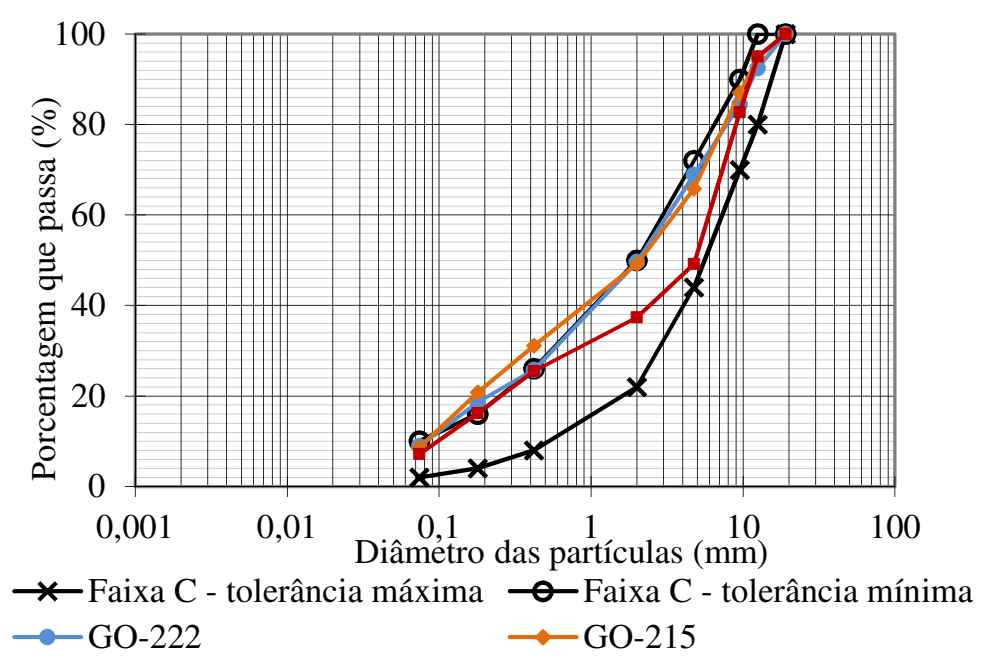

Figura 1: Curvas granulométricas das misturas e limites da Faixa $C$

Os resultados de densidade aparente, massa específica máxima medida da mistura (Gmm) e teor de ligante são apresentados na Tabela 5, bem como os parâmetros de volumetria. No entanto, conforme já relatado, não foi possível ter acesso ao projeto de mistura da G0-222. Por outro lado, sabe-se que o ligante mais utilizado na região de estudo é o CAP 50/70 e a variação da densidade desse ligante para a do CAP 30/45 ou AMP é pequena (Prudente, 2015). Para fins de estimativa, optou-se por adotar a densidade do ligante apresentada para a GO-147 nos cálculos volumétricos a partir da Gmm da GO-222, observando-se que a alteração desse valor, usando a densidade do CAP 30/45 ou AMP, pouco mudaria os parâmetros volumétricos. Observa-se diferença entre a densidade máxima teórica (DMT) e a Gmm encontrada por meio do Rice test que considera a absorção do ligante pelos agregados, gerando volume de vazios (Vv) menor da mistura do que o Vv determinado com a DMT (Bernucci et al., 2006). No Brasil, a maioria dos projetos de mistura de CA ainda utiliza a DMT, podendo levar à escolha incorreta do teor de ligante e causar degradação prematura nos revestimentos.

Segundo a ES 031 (DNIT, 2006a), para camadas de rolamento, o Vv deve atender ao intervalo de 3 a $5 \%$, sendo que esse limite foi atendido. No entanto, os resultados dos ensaios realizados com os CPs extraídos das pistas demonstraram que os revestimentos das três rodovias apresentaram porcentagem de vazios acima do limite estabelecido tanto quando se utiliza a Gmm quanto a DMT. Quanto à RBV, a mesma norma especifica valores de 75 a 82\%. Novamente, os valores informados pelo projeto atendem o limite estabelecido. Entretanto, em nenhum CP extraído das rodovias esses valores foram atendidos. Esses resultados demonstram problemas advindos da dosagem Marshall, principalmente com relação às determinações das densidades e à forma de compactação das misturas. Além disso, eventuais problemas construtivos podem estar associados a essa questão. 
Tabela 5: Características obtidas para as misturas asfálticas

\begin{tabular}{|c|c|c|c|c|c|c|c|c|c|}
\hline Rodovia & Origem dos resultados & Densidac & mistura & $\begin{array}{c}\mathrm{Gmb} \\
\left(\mathrm{g} / \mathrm{cm}^{3}\right)\end{array}$ & $\begin{array}{l}\text { Vv } \\
(\%)\end{array}$ & $\begin{array}{l}\text { VCB } \\
(\%)\end{array}$ & $\begin{array}{l}\text { VAM } \\
\text { (\%) }\end{array}$ & $\begin{array}{l}\text { RBV } \\
(\%)\end{array}$ & $\begin{array}{c}\text { Teor de } \\
\text { ligante } \\
(\%)\end{array}$ \\
\hline \multirow{2}{*}{ GO-222 } & \multirow{2}{*}{ Ensaios laboratoriais } & $\mathrm{Gmm}$ & 2,581 & 2,402 & 6,9 & 10,39 & 17,32 & 59,98 & 4,5 \\
\hline & & $\mathrm{Gmm}$ & 2,571 & 2,417 & 6,0 & 10,53 & 16,50 & 63,80 & 4,5 \\
\hline \multirow{5}{*}{ GO-215 } & Projeto & DMT & 2,500 & 2,406 & 4,0 & 13,24 & 17,24 & 79,00 & 5,8 \\
\hline & \multirow{4}{*}{ Ensaios laboratoriais } & DMT & 2,512 & 2,262 & 10,0 & 11,54 & 21,49 & 53,70 & 5,4 \\
\hline & & $\mathrm{Gmm}$ & 2,458 & 2,262 & 8,0 & 11,54 & 19,51 & 59,16 & 5,4 \\
\hline & & DMT & 2,511 & 2,279 & 9,2 & 11,67 & 20,92 & 55,81 & 5,4 \\
\hline & & $\mathrm{Gmm}$ & 2,466 & 2,279 & 7,6 & 11,67 & 19,25 & 60,66 & 5,4 \\
\hline \multirow{5}{*}{ GO-147 } & Projeto & DMT & 2,501 & 2,410 & 3,6 & 11,61 & 15,21 & 76,20 & 5,0 \\
\hline & \multirow{4}{*}{ Ensaios laboratoriais } & DMT & 2,622 & 2,360 & 10,0 & 12,20 & 22,18 & 55,02 & 5,4 \\
\hline & & $\mathrm{Gmm}$ & 2,510 & 2,360 & 6,0 & 12,20 & 18,17 & 67,15 & 5,4 \\
\hline & & DMT & 2,613 & 2,375 & 9,1 & 12,78 & 21,87 & 58,42 & 5,6 \\
\hline & & $\mathrm{Gmm}$ & 2,517 & 2,375 & 5,6 & 12,78 & 18,42 & 69,36 & 5,6 \\
\hline
\end{tabular}

Obs.: DMT = Densidade Máxima Teórica; $\mathrm{Gmm}=$ massa específica máxima medida; $\mathrm{Gmb}=$ massa específica aparente; $\mathrm{Vv}=$ Volume de Vazios; $\mathrm{VCB}=$ Volume de Vazios Preenchido com Betume; VAM = Volume de Vazios do Agregado Mineral; RBV = Relação Betume Vazios.

Para o tamanho nominal máximo obtido, a ES 031 (DNIT, 2006a) exige valor mínimo de VAM = 15\%. Os CPs das três rodovias atenderam ao especificado. Já com relação ao teor de asfalto, na GO-215, observou-se que a quantidade determinada nos ensaios foi $0,4 \%$ menor que aquela estabelecida em projeto. Situação contrária ocorreu na G0-147. Segundo Prudente (2015), se a quantidade de ligante estiver 0,5\% abaixo do teor de projeto, o revestimento pode apresentar desagregação ou trincamento e se estiver 0,5\% acima, pode apresentar exsudação e deformação permanente. Nesta pesquisa, não se teve acesso ao projeto da mistura utilizada na GO-222. No entanto, pesquisas da região relatam que o teor ideal de asfalto se aproxima de 5\% de ligante (Coelho Jr. e Rocha, 2013). Prudente (2015) realizou diferentes dosagens, variando a granulometria dos agregados (Faixa B e C) e o tipo de CAP utilizado (CAP $30 / 45$ e 50/70) e obteve teores de asfalto variando entre 4,8 e 5,7\%, sendo os maiores valores obtidos para a Faixa C. Com base nesses dados, pode-se considerar como hipótese que os valores determinados nos CPs da GO-222 estão abaixo do usualmente encontrado.

\subsubsection{Parâmetros mecânicos}

A Tabela 6 apresenta os resultados de RT e MR. Os valores de RT foram superiores ao limite mínimo de 0,65 MPa estabelecido pela ES 031 (DNIT, 2006a). Observa-se que os resultados de RT e MR da GO-147 foram superiores aos da GO-215. Vasconcelos et al. (2013) realizaram estudo com diferentes granulometrias e ligantes asfálticos para caracterização mecânica de misturas. Observou-se que a granulometria foi o fator preponderante na RT e no MR. Os autores ressaltaram ainda que o ligante também influenciou nos parâmetros mecânicos, com tendência a valores menores de RT e MR quanto menor sua consistência. Aragão et al. (2016) avaliaram a influência de propriedades morfológicas de agregados diferentes (seixo rolado e pedra britada) no comportamento mecânico das misturas. Entre as conclusões obtidas, observaram melhor correlação das propriedades dos agregados graúdos com a resistência das misturas ao dano do que as propriedades dos agregados miúdos. Os autores verificaram que a forma e a textura dos agregados afetam a resistência à deformação permanente. Analisando-se as curvas granulométricas (Figura 1), observa-se que a porcentagem de agregados graúdos na mistura da G0-147 é maior do que a da GO-215, podendo gerar maior resistência da mistura da G0-147. De acordo com o a Tabela 4, os agregados utilizados no CA da GO-147 tiveram como rocha de origem o micaxisto e o ligante utilizado foi o CAP 50/70. Já na GO-215, os agregados são originados de rocha granítica e não apresentaram boa adesividade com o ligante CAP 50/70. Optou-se, então, pela troca do CAP 50/70 pelo AMP 60/85, um asfalto modificado por polímero que possui melhor característica adesiva, coesiva e maior resistência à deformação permanente.

Bernucci et al. (2006) indicam a faixa de 2000 a 8000 MPa para valores típicos de MR para CA a $25^{\circ} \mathrm{C}$, sendo os menores valores encontrados para misturas com asfaltos modificados por polímeros ou por 
borracha e os maiores para misturas com asfaltos de consistência dura. Essa variação foi percebida com os resultados de MR menores para a GO-215, que utilizou AMP, e maiores para a GO-147, que utilizou o CAP 50/70. Sendo assim, conclui-se que as variações dos resultados de RT e MR para os revestimentos ocorreram pelas diferenças na granulometria dos agregados e no ligante utilizado. Quanto à relação MR/RT, pode-se realizar uma avaliação preliminar da vida de fadiga: quanto menor o valor obtido para essa razão, melhor seria o comportamento da mistura (Bock et al., 2009). A menor relação MR/RT foi obtida para a G0-147, destacando o seu melhor desempenho em relação à GO-215.

Tabela 6: Resultados de RT e MR

\begin{tabular}{ccccc}
\hline Rodovia & Amostra & RT (MPa) & MR (MPa) & MR/RT \\
\hline \multirow{2}{*}{ GO-215 } & 1 & 0,909 & 4423 & 4866 \\
& 2 & 1,063 & 5021 & 4723 \\
& 3 & 1,020 & 5049 & 4950 \\
\hline \multirow{2}{*}{ GO-147 } & 1 & 1,760 & 7196 & 4089 \\
& 2 & 1,819 & 6869 & 3776 \\
\hline
\end{tabular}

Obs.: RT =Resistência à Tração; MR = Módulo de Resiliência.

\subsection{Ensaios de campo}

\subsubsection{Viga Benkelman}

Geralmente, quanto maior o valor de $\mathrm{D}_{0}$, menos rígida é a estrutura e maior o seu comprometimento estrutural, sendo valores preocupantes os superiores a $100\left(\mathrm{x} 10^{-2} \mathrm{~mm}\right)$. A Tabela 7 apresenta os valores de $\mathrm{D}_{0}$ das rodovias estudadas por Costa (2013), Hómez (2014) e Rezende (2014) e pela presente pesquisa no ano de 2015. Apesar dos levantamentos não serem realizados na mesma época do ano, foi feita a correção sazonal nas análises com base no PRO 011 (DNER, 1979). Bernucci et al. (2006) indicam, para um revestimento de CA e base granular em boa condição estrutural, valores típicos de $\mathrm{D}_{0}$ na ordem de 30 a 50 (x10-2 mm). Em pavimentos novos, Sachet (2007) e Costa (2013) encontraram valores variando de 40 a $69\left(\times 10^{-2} \mathrm{~mm}\right)$. Trechos que apresentam menos de $50 \%$ dos valores considerados coerentes com valores para rodovias recém-restauradas, podem indicar falhas construtivas ou projetos inadequados.

A G0-222 foi restaurada em 2012, quando 89\% dos valores obtidos foram inferiores a 69 (x 10-2 $\mathrm{mm}$ ), indicando um pavimento com boa resistência estrutural. No entanto, em 2015, esse valor foi reduzido para $65 \%$, o que pode indicar queda no desempenho. Sabe-se que o ciclo de vida do pavimento pode se dar em três fases na medida em que a estrutura é submetida às repetições de carga: fase de consolidação (deflexão diminui devido à consolidação das camadas); fase elástica (define a vida útil do pavimento e as deflexões são praticamente constantes); fase de fadiga (camadas perdem sua capacidade estrutural). Na GO-222, após três anos de conclusão da restauração, o pavimento provavelmente está na fase elástica, caminhando para a fase de fadiga.

Já as rodovias GO-215 e GO-147 foram restauradas e avaliadas pela primeira vez em 2014, apresentando, respectivamente, $84 \%$ e 54\% dos valores menores que 69 (x 10-2 $\mathrm{mm})$. A avaliação feita em 2015 mostrou diminuição desse parâmetro na GO-215 (de 84\% para 75\%) e aumento na G0-147 (de 54\% para 90\%). De acordo com seu ciclo de vida, é possível que na GO-215 o pavimento já esteja na fase elástica e na GO-147 ainda na fase de consolidação. Essa diferença pode estar relacionada com o tráfego (frequência e carga) existente em cada rodovia. No entanto, como o tráfego não está registrado nos projetos, não há como avaliar sua influência.

Na Tabela 7 observa-se que os valores do desvio padrão, erro padrão da média e coeficiente de variação diminuíram ao longo do tempo, o que indica maior homogeneidade dos trechos. Esse fato pode ser explicado pela acomodação da estrutura após a abertura ao tráfego, gerando menor variação no comportamento. Comparando os dados em termos de média global, verifica-se que na GO-222, em 2015, o valor de deflexão foi maior do que 2012. Mesmo assim, o valor de $\mathrm{D}_{0}$ obtido em 2015 ainda pode ser considerado satisfatório. Para a GO-215, a alteração de $\mathrm{D}_{0}$ foi pequena, o que demonstra que não ocorreu 
variação no comportamento. Já na G0-147 o valor da média em 2015 (56 x10-2mm) foi menor do que em 2014 (69 x10-2 $\mathrm{mm})$. Esses resultados são coerentes com o que foi discutido anteriormente quanto ao ciclo de vida dos pavimentos. Em outra forma de analisar os dados, os trechos foram subdivididos em segmentos homogêneos (Tabela 8), conforme a PRO 011 (DNER, 1979). Ressalta-se que a subjetividade da delimitação dos segmentos, ditada pela natureza do problema, é inevitável.

Tabela 7: Resumo das medidas de deflexão máxima (x10-2 $\mathrm{mm}$ )

\begin{tabular}{ccccccc}
\hline & \multicolumn{2}{c}{ GO-222 } & \multicolumn{2}{c}{ GO-215 } & \multicolumn{2}{c}{ GO-147 } \\
\cline { 2 - 6 } D0 (0,01 mm) & $\begin{array}{c}2012 \\
\text { (Costa, 2013) }\end{array}$ & \multirow{2}{*}{$2015^{*}$} & $\begin{array}{c}2014 \\
\text { (Hómez, 2014) }\end{array}$ & 2015* & $\begin{array}{c}2014 \\
\text { (Rezende, 2014) }\end{array}$ & 2015* \\
\hline Média & 43,08 & 65,75 & 56,93 & 63,36 & 69,19 & 56,22 \\
Mediana & 41,00 & 64,09 & 53,78 & 60,88 & 68,02 & 55,58 \\
Desvio Padrão & 20,25 & 14,30 & 20,06 & 13,08 & 18,04 & 11,44 \\
Erro padrão da média & 1,02 & 0,71 & 1,00 & 0,65 & 0,90 & 0,57 \\
Coeficiente de Variação & 0,47 & 0,22 & 0,35 & 0,21 & 0,26 & 0,20 \\
\hline
\end{tabular}

Obs.: $\mathrm{D}_{0}=$ deflexão máxima; * Dados obtidos nesta pesquisa.

Tabela 8: Segmentos homogêneos e deflexão característica

\begin{tabular}{|c|c|c|c|c|c|c|c|c|c|}
\hline \multirow{2}{*}{ Rodovia } & \multirow{2}{*}{ Ano } & \multirow{2}{*}{ Parâmetros } & \multicolumn{7}{|c|}{ Segmentos } \\
\hline & & & 1 & 2 & 3 & 4 & 5 & 6 & 7 \\
\hline \multirow{12}{*}{$\begin{array}{l}\underset{N}{N} \\
\text { O্ঠ }\end{array}$} & \multirow{6}{*}{$\begin{array}{c}2012 \text { (Costa, } \\
2013)\end{array}$} & $\mathrm{Ei}$ & 300 & 359 & 375 & 476 & 541 & 573 & 666 \\
\hline & & Ef & 358 & 374 & 475 & 540 & 572 & 665 & 700 \\
\hline & & Extensão (m) & 1160 & 300 & 2000 & 1280 & 620 & 1840 & 680 \\
\hline & & $D_{\text {omédio }}(0,01 \mathrm{~mm})$ & 39,46 & 55,88 & 44,36 & 58,38 & 38,04 & 31,90 & 44,49 \\
\hline & & $\mathrm{CV}$ & 0,37 & 0,40 & 0,44 & 0,35 & 0,43 & 0,57 & 0,40 \\
\hline & & $\mathrm{Dc}(0,01 \mathrm{~mm})$ & 70,07 & 101,78 & 83,20 & 102,45 & 70,67 & 65,03 & 81,05 \\
\hline & \multirow{6}{*}{$2015^{*}$} & $\mathrm{Ei}$ & 300 & 401 & 501 & 558 & 582 & 683 & - \\
\hline & & Ef & 400 & 500 & 557 & 581 & 682 & 700 & - \\
\hline & & Extensão (m) & 2000 & 1980 & 1120 & 460 & 2000 & 340 & - \\
\hline & & $D_{\text {omédio }}(0,01 \mathrm{~mm})$ & 63,92 & 70,87 & 68,65 & 66,88 & 61,86 & 58,73 & - \\
\hline & & $\mathrm{CV}$ & 0,22 & 0,22 & 0,19 & 0,25 & 0,20 & 0,14 & - \\
\hline & & $\mathrm{Dc}(0,01 \mathrm{~mm})$ & 101,08 & 112,38 & 105,88 & 108,34 & 96,90 & 87,41 & - \\
\hline \multirow{12}{*}{ 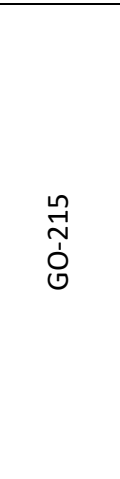 } & \multirow{6}{*}{$\begin{array}{c}2014 \text { (Hómez, } \\
\text { 2014) }\end{array}$} & $\mathrm{Ei}$ & 600 & 693 & 741 & 841 & 918 & - & - \\
\hline & & Ef & 692 & 740 & 840 & 917 & 1000 & - & - \\
\hline & & Extensão (m) & 1840 & 940 & 1980 & 1520 & 1640 & - & - \\
\hline & & $D_{\text {Omédio }}(0,01 \mathrm{~mm})$ & 74,49 & 64,78 & 53,39 & 57,16 & 54,93 & - & - \\
\hline & & $\mathrm{CV}$ & 0,44 & 0,30 & 0,23 & 0,22 & 0,22 & - & - \\
\hline & & $\mathrm{Dc}(0,01 \mathrm{~mm})$ & 107,41 & 83,95 & 65,45 & 69,5 & 67,05 & - & - \\
\hline & \multirow{6}{*}{$2015 *$} & $\mathrm{Ei}$ & 600 & 701 & 758 & 859 & 960 & - & - \\
\hline & & Ef & 700 & 757 & 858 & 959 & 1000 & - & - \\
\hline & & Extensão (m) & 2000 & 1120 & 2000 & 2000 & 800 & - & - \\
\hline & & Domédio $(0,01 \mathrm{~mm})$ & 70,58 & 71,64 & 53,25 & 60,57 & 65,83 & - & - \\
\hline & & $\mathrm{CV}$ & 0,20 & 0,22 & 0,13 & 0,14 & 0,13 & - & - \\
\hline & & $\mathrm{Dc}(0,01 \mathrm{~mm})$ & 109,67 & 113,63 & 78,15 & 89,85 & 96,87 & - & - \\
\hline \multirow{12}{*}{$\begin{array}{l}\text { 今े } \\
\text { 今̀ } \\
\text { Oे }\end{array}$} & \multirow{6}{*}{$\begin{array}{c}2014 \text { (Re- } \\
\text { zende, 2014) }\end{array}$} & $\mathrm{Ei}$ & 1000 & 1101 & 1201 & 1301 & - & - & - \\
\hline & & $\mathrm{Ef}$ & 1100 & 1200 & 1300 & 1400 & - & - & - \\
\hline & & Extensão (m) & 2000 & 1980 & 1980 & 1980 & - & - & - \\
\hline & & $D_{\text {omédio }}(0,01 \mathrm{~mm})$ & 59,98 & 58,69 & 80,86 & 77,32 & - & - & - \\
\hline & & $\mathrm{CV}$ & 0,25 & 0,20 & 0,20 & 0,22 & - & - & - \\
\hline & & $\mathrm{Dc}(0,01 \mathrm{~mm})$ & 74,81 & 70,55 & 97,18 & 94,17 & - & - & - \\
\hline & \multirow{6}{*}{$2015^{*}$} & $\mathrm{Ei}$ & 1000 & 1094 & 1194 & 1291 & 1350 & - & - \\
\hline & & Ef & 1093 & 1193 & 1290 & 1349 & 1400 & - & - \\
\hline & & Extensão (m) & 1860 & 1980 & 1920 & 1160 & 1000 & - & - \\
\hline & & Domédio $(0,01 \mathrm{~mm})$ & 56,04 & 47,95 & 60,20 & 58,46 & 62,63 & - & - \\
\hline & & $\mathrm{CV}$ & 0,19 & 0,14 & 0,12 & 0,13 & 0,30 & - & - \\
\hline & & $\mathrm{Dc}(0,01 \mathrm{~mm})$ & 86,63 & 71,30 & 87,82 & 85,75 & 106,06 & - & - \\
\hline
\end{tabular}

Obs.: Ei = Estaca inicial do segmento; $\mathrm{Ef}=$ Estaca final do segmento; $\mathrm{D}_{0}$ médio = Deflexão máxima média; $\mathrm{CV}=\mathrm{Coeficiente}$ de Variação para $\mathrm{D}_{0}$; Dc = Deflexão Característica; * Dados obtidos nesta pesquisa. 
Como não existem dados sobre o estudo de tráfego, foram definidos três cenários. Os cálculos da deflexão admissível ( $D_{\text {adm }}$ ) foram realizados de acordo com a PRO 011 (DNER, 1979), resultando: tráfego leve $\left(\mathrm{N}=10^{5}\right.$ e $\left.\mathrm{D}_{\mathrm{adm}}=134,90 \times 10^{-2} \mathrm{~mm}\right)$, tráfego médio $\left(\mathrm{N}=10^{6}\right.$ e $\left.\mathrm{D}_{\mathrm{adm}}=89,95 \times 10^{-2} \mathrm{~mm}\right)$ e tráfego elevado $\left(\mathrm{N}=10^{7}\right.$ e $\left.\mathrm{D}_{\mathrm{adm}}=59,98 \times 10^{-2} \mathrm{~mm}\right)$. A partir daí, foram obtidas algumas hipóteses:

- Para $\mathrm{N}=10^{5}$ todos os segmentos das rodovias GO-222, GO-215 e GO-147 apresentaram deflexões abaixo de $\mathrm{D}_{\text {adm }}$ nas duas etapas de avaliação e classificados com boa qualidade estrutural;

- Para $\mathrm{N}=10^{6}$ a GO-222, em 2012, apresentou dois de seus segmentos com $\mathrm{D}_{0}$ acima do admissível, sendo classificados como regular. 0 mesmo aconteceu com cinco dos seis segmentos dessa rodovia na avaliação de 2015. Já para a GO-215, nos dois anos de avaliação, três segmentos foram classificados como regular. Na GO-147, em 2014, dois segmentos foram classificados como regular e em 2015, apenas um dos segmentos apresentou essa condição. Os demais foram classificados como de boa qualidade;

- Para $\mathrm{N}=10^{7}$, nas duas etapas de avaliação, todos os segmentos das três rodovias apresentaram deflexões acima de $\mathrm{D}_{\mathrm{adm}}$ e foram classificados como regular.

Com base nessas classificações, observa-se que a restauração proposta para as três rodovias pode não ser suficiente para um tráfego pesado. Em alguns locais, a limitação já aparece para um tráfego médio. Essa constatação irá impactar na redução da durabilidade da estrutura restaurada. No entanto, devese ressaltar que o problema não está na técnica utilizada, mas sim na forma empírica que o projeto foi definido, sem uso adequado de parâmetros mecanísticos e sem o conhecimento do tráfego existente.

\subsubsection{Levantamento visual contínuo}

Na Tabela 9, têm-se os valores do Índice de Gravidade Global (IGG) e das médias das flechas de trilha de roda interna e externa. Na GO-222, no primeiro ano de análise foram identificados defeitos como trincas do tipo couro de jacaré que tiveram uma variação significativa na análise do ano de 2015, com frequência relativa aumentando de 9,2\% para 50,6\%. Costa (2013) levantou a hipótese de que na G0-222 as trincas que iniciaram no revestimento novo ou mesmo as panelas encontradas poderiam ser reflexo de defeitos do pavimento antigo ou trincas de retração devido à base cimentada. Como não foram observadas intervenções no pavimento no intervalo das duas avaliações, percebe-se que a ocorrência dos defeitos só aumentou. 0 estado do pavimento passou de ótimo para regular. Outro fato a se observar é a espessura do revestimento que, de acordo com o projeto, foi de $4 \mathrm{~cm}$ em alguns trechos e $3 \mathrm{~cm}$ em outros. Tal espessura se mostrou insuficiente, visto que a rodovia apresentou vários defeitos apenas dois anos após a restauração. Nas GO-215 e GO-147, o defeito mais observado foi o desgaste, seguido por trincas do tipo "couro de jacaré". Nota-se que nos dois casos, as boas condições foram mantidas, comparando-se o conceito do pavimento na primeira e na segunda avaliação.

Tabela 9: Resultados da avaliação funcional

\begin{tabular}{|c|c|c|c|c|c|c|c|}
\hline \multirow[b]{2}{*}{ Norma } & \multirow[b]{2}{*}{ Parâmetros } & \multicolumn{2}{|c|}{ GO-222 } & \multicolumn{2}{|l|}{ GO-215 } & \multicolumn{2}{|l|}{ GO-147 } \\
\hline & & $\begin{array}{c}2012 \\
\text { (Costa, 2013) } \\
\end{array}$ & 2015* & $\begin{array}{c}2014 \text { (Hómez, } \\
\text { 2014) } \\
\end{array}$ & 2015* & $\begin{array}{c}2014 \text { (Rezende, } \\
\text { 2014) }\end{array}$ & 2015* \\
\hline PRO 006 & IGG & 17 & 44 & 19 & 10 & 32 & 22 \\
\hline (DNIT, & Conceito & Ótimo & Regular & Ótimo & Ótimo & Bom & Bom \\
\hline 2003b) & Média TRI e TRE (mm) & 0,2 & 1,4 & 0,1 & 0,3 & 0,5 & 1,1 \\
\hline & TR (\%) & - & 17,24 & - & 2,11 & - & 6,40 \\
\hline PRO 007 & DE (\%) & - & 0,01 & - & 3,11 & - & 3,26 \\
\hline (DNIT, 2003c) & $\begin{array}{l}\text { Maior valor de flecha } \\
\text { medido }(\mathrm{mm})\end{array}$ & & 8 & & 3 & & 4 \\
\hline
\end{tabular}

Obs.: IGG = Índice de Gravidade Global; TRI = Trilha de Roda Interna; TRE = Trilha de Roda Externa; TR = porcentagem de área com trincas; DE = porcentagem de área com desgaste; * Dados obtidos nesta pesquisa.

Em termos de deformação permanente, Choi (2013) e Lacroix (2013) consideram que valores de até 12,5 mm são satisfatórios. Medina e Motta (2015) ressaltam que em alguns países, o valor admissível do 
afundamento para autoestradas é de $10 \mathrm{~mm}$ e para estradas de menor tráfego poderia chegar a $16 \mathrm{~mm}$, mas se atingir $20 \mathrm{~mm}$ recomenda-se reparo imediato. Ainda de acordo com o Manual de Restauração de Pavimentos Asfálticos (DNIT, 2006b), seriam indicativos de comprometimento estrutural valores como trincamento por fadiga maior que $20 \%$ da área e afundamentos nas trilhas de roda maiores que $12 \mathrm{~mm} .0$ mesmo manual admite como faixas de aceitação de área trincada valores de 15 a $40 \%$ e desgaste de 15 a $40 \%$. De maneira geral, os revestimentos dos trechos avaliados se mostraram adequados em termos de deformação permanente. No entanto, percebe-se aumento nos valores médios desse parâmetro nas rodovias GO-222 e G0-147 durante os anos de monitoramento. Quanto à PRO 007 (DNIT, 2003b), avaliou-se a área trincada e desgaste apenas em 2015 (Tabela 9). Na GO-147, em 6,40\% da área avaliada foi observada a presença de trincas e em 3,26\%, desgaste. Na GO-215, 2,11\% da área apresentou trincas e $3,11 \%$ apresentou desgaste. 0 pior caso foi da G0-222, onde a porcentagem da área trincada foi de $17,24 \%$, apesar da área com desgaste ter apresentado valor inexpressível. Além disso, os valores mais altos das flechas foram encontrados nessa rodovia. Quanto aos limites já citados, verifica-se que a GO222 apresentou valores preocupantes de porcentagem de área trincada e afundamento nas trilhas de roda em alguns pontos. Esses resultados são coerentes com as análises do IGG, onde a GO-222 foi classificada como regular em 2015. Esses resultados também corroboram com a avaliação dos segmentos homogêneos quanto ao tráfego.

\subsubsection{Penetrômetro Dinâmico de Cone}

A espessura de projeto para a base da GO-222 era de $15 \mathrm{~cm}$ e para as bases das GO-215 e GO-147 era de $18 \mathrm{~cm}$. Pela Tabela 10, em termos de média, somente a G0-215 não atendeu essa definição em 2015. Para a G0-215, Hómez (2014) já havia notado esse problema, afirmando que essa variação poderia interferir no seu desempenho. Esse fato se agravou no ano seguinte. Em termos de média, houve redução na espessura das bases nas GO-222 e GO-215 entre os períodos avaliados. A alteração na GO-222 foi pequena, fato justificado pela variabilidade do ensaio. Além disso, após a liberação da rodovia ao tráfego e com a acomodação da estrutura, pode ocorrer redução na espessura. Na GO-215, percebe-se que a variação da espessura média da base foi maior. Por se tratar de um material granular, esse fato pode estar associado à presença de agregados graúdos logo abaixo da ponta do penetrômetro. Em relação à resistência, o valor médio do índice de penetração (DN) pouco se alterou com o passar dos anos.

Tabela 10: Estratigrafia e valores de DN

\begin{tabular}{|c|c|c|c|c|c|c|}
\hline \multirow{2}{*}{ Rodovia } & \multirow{2}{*}{ Ano } & \multirow{2}{*}{ Camada } & \multirow{2}{*}{$\begin{array}{l}\text { Espessura } \\
\text { média }(\mathrm{cm})\end{array}$} & \multicolumn{3}{|c|}{ DN (mm/golpes) } \\
\hline & & & & Média & Desvio Padrão & Coef. de Variação \\
\hline \multirow{6}{*}{ GO-222 } & \multirow{3}{*}{$\begin{array}{l}2012 \\
\text { (Costa, 2013) }\end{array}$} & Base & 20,84 & 2,51 & 0,73 & 0,29 \\
\hline & & Sub-base & 15,78 & 4,33 & 1,75 & 0,41 \\
\hline & & Subleito & 13,40 & 7,71 & 3,68 & 0,48 \\
\hline & \multirow{3}{*}{$2015^{*}$} & Base & 18,88 & 2,67 & 0,88 & 0,33 \\
\hline & & Sub-base & 18,97 & 4,21 & 1,39 & 0,33 \\
\hline & & Subleito & 24,04 & 6,19 & 3,30 & 0,53 \\
\hline \multirow{6}{*}{ GO-215 } & \multirow{3}{*}{$\begin{array}{l}2014 \\
\text { (Hómez, 2014) }\end{array}$} & Base & 20,00 & 2,24 & 0,77 & 0,34 \\
\hline & & Sub-base & 18,00 & 4,06 & 2,65 & 0,65 \\
\hline & & Subleito & 27,00 & 6,19 & 1,80 & 0,29 \\
\hline & \multirow{3}{*}{$2015^{*}$} & Base & 15,78 & 2,42 & 0,94 & 0,39 \\
\hline & & Sub-base & 18,89 & 4,35 & 2,41 & 0,56 \\
\hline & & Subleito & 26,70 & 9,08 & 3,37 & 0,37 \\
\hline \multirow{3}{*}{ GO-147 } & \multirow{3}{*}{$2015^{*}$} & Base & 19,87 & 2,63 & 0,52 & 0,20 \\
\hline & & Sub-base & 17,14 & 4,57 & 2,21 & 0,48 \\
\hline & & Subleito & 24,92 & 8,39 & 3,08 & 0,37 \\
\hline
\end{tabular}

Obs.: * Dados obtidos nesta pesquisa. $\mathrm{DN}$ = índice de penetração.

O coeficiente de variação (CV) pouco se alterou nas avaliações, tendo o menor resultado para a base da GO-147. Segundo Andriotti (2010), valores elevados de CV representam amostras com grande heterogeneidade e valores abaixo de 0,40 refletem homogeneidade da amostra. Neste estudo, os CV das bases 
recicladas foram menores que 0,40 (Tabela 10). Nas camadas de sub-base e subleito, alguns valores de CV foram superiores a 0,40 , constatando que essas camadas podem apresentar significativa variação de resistência. Esse fato é considerado um aspecto negativo no comportamento da estrutura e, se não for considerado no projeto, a solução geral adotada pode ser satisfatória em alguns pontos da rodovia, mas em outros não.

\subsection{Retroanálises}

Como não foi possível a realização do ensaio para determinação do módulo do revestimento na GO-222, admitiu-se o valor mínimo de $2000 \mathrm{MPa}$. No caso dos revestimentos da G0-215 e GO-147, o módulo de entrada foi definido como aproximadamente $95 \%$ do menor resultado encontrado nos ensaios de laboratório (4200 MPa para a GO-215 e $6500 \mathrm{MPa}$ para a G0-147). Com os resultados de DCP, definiu-se a quantidade e as espessuras das camadas. No caso da G0-147, para 2014 os valores informados foram baseados no projeto. Os valores de módulo obtidos são apresentados na Tabela 11.

Tabela 11: Resultados obtidos nas retroanálises

\begin{tabular}{|c|c|c|c|c|c|c|c|c|c|c|}
\hline \multirow{2}{*}{ Rodovia } & \multirow{2}{*}{ Ano } & \multirow{2}{*}{ Parâmetro } & \multirow{2}{*}{ Camada } & \multicolumn{7}{|c|}{ Segmentos } \\
\hline & & & & 1 & 2 & 3 & 4 & 5 & 6 & 7 \\
\hline \multirow{12}{*}{ GO-222 } & \multirow{6}{*}{$\begin{array}{c}2012 \\
\text { (Costa, } \\
2013)\end{array}$} & \multirow{2}{*}{$\begin{array}{l}\text { Espessura } \\
\text { média }(\mathrm{cm})\end{array}$} & Base & 17 & 12 & 20 & 27 & 28 & 20 & 21 \\
\hline & & & Sub-base & 17 & 14 & 15 & 17 & 11 & 17 & 20 \\
\hline & & \multirow{4}{*}{$\begin{array}{l}\text { Módulo } \\
\text { (MPa) }\end{array}$} & $\mathrm{CA}$ & 3000 & 2300 & 2300 & 2300 & 4000 & 2300 & 2000 \\
\hline & & & Base & 600 & 400 & 500 & 300 & 500 & 400 & 350 \\
\hline & & & Sub-base & 300 & 250 & 220 & 200 & 450 & 250 & 200 \\
\hline & & & Subleito & 145 & 125 & 150 & 105 & 120 & 110 & 90 \\
\hline & \multirow{6}{*}{$2015^{*}$} & \multirow{2}{*}{$\begin{array}{l}\text { Espessura } \\
\text { média }(\mathrm{cm})\end{array}$} & Base & 18 & 19 & 19 & 19 & 19 & 21 & - \\
\hline & & & Sub-base & 21 & 19 & 19 & 21 & 17 & 18 & - \\
\hline & & \multirow{4}{*}{$\begin{array}{l}\text { Módulo } \\
\text { (MPa) }\end{array}$} & $\mathrm{CA}$ & 2000 & 2000 & 2000 & 2000 & 2000 & 2000 & - \\
\hline & & & Base & 200 & 180 & 180 & 190 & 230 & 250 & - \\
\hline & & & Sub-base & 175 & 150 & 140 & 150 & 160 & 170 & - \\
\hline & & & Subleito & 100 & 90 & 100 & 100 & 100 & 100 & - \\
\hline \multirow{12}{*}{ GO-215 } & \multirow{6}{*}{$\begin{array}{c}2014 \\
\text { (Hómez, } \\
\text { 2014) }\end{array}$} & \multirow{2}{*}{$\begin{array}{l}\text { Espessura } \\
\text { média }(\mathrm{cm})\end{array}$} & Base & 23 & 18 & 17 & 17 & 19 & & - \\
\hline & & & Sub-base & 19 & 22 & 17 & 17 & 19 & - & - \\
\hline & & \multirow{4}{*}{$\begin{array}{l}\text { Módulo } \\
\text { (MPa) }\end{array}$} & $\mathrm{CA}$ & 2000 & 2000 & 2000 & 2000 & 2000 & - & - \\
\hline & & & Base & 240 & 240 & 300 & 260 & 280 & - & - \\
\hline & & & Sub-base & 190 & 190 & 280 & 200 & 200 & - & - \\
\hline & & & Subleito & 80 & 80 & 100 & 100 & 100 & - & - \\
\hline & \multirow{6}{*}{$2015^{*}$} & \multirow{2}{*}{$\begin{array}{l}\text { Espessura } \\
\text { média }(\mathrm{cm})\end{array}$} & Base & 17 & 15 & 13 & 19 & 15 & - & - \\
\hline & & & Sub-base & 19 & 21 & 19 & 15 & 23 & - & - \\
\hline & & \multirow{4}{*}{$\begin{array}{l}\text { Módulo } \\
\text { (MPa) }\end{array}$} & $\mathrm{CA}$ & 4200 & 4200 & 4200 & 4200 & 4200 & - & - \\
\hline & & & Base & 240 & 230 & 330 & 230 & 210 & - & - \\
\hline & & & Sub-base & 190 & 190 & 270 & 190 & 180 & - & - \\
\hline & & & Subleito & 70 & 70 & 100 & 100 & 90 & - & - \\
\hline \multirow{12}{*}{ GO-147 } & \multirow{6}{*}{$\begin{array}{c}2014 \\
\text { (Rezende, } \\
\text { 2014) }\end{array}$} & \multirow{2}{*}{$\begin{array}{l}\text { Espessura } \\
\text { média }(\mathrm{cm})\end{array}$} & Base & 18 & 18 & 18 & 18 & - & & - \\
\hline & & & Sub-base & 22 & 22 & 22 & 22 & - & - & - \\
\hline & & \multirow{4}{*}{$\begin{array}{l}\text { Módulo } \\
\text { (MPa) }\end{array}$} & $\mathrm{CA}$ & 2000 & 2000 & 2000 & 2000 & - & - & - \\
\hline & & & Base & 300 & 300 & 250 & 200 & - & - & - \\
\hline & & & Sub-base & 200 & 200 & 150 & 130 & - & - & - \\
\hline & & & Subleito & 100 & 100 & 80 & 75 & - & - & - \\
\hline & \multirow{6}{*}{ 2015* } & \multirow{3}{*}{$\begin{array}{l}\text { Espessura } \\
\text { média }(\mathrm{cm})\end{array}$} & Base & 22 & 19 & 22 & 17 & 16 & - & - \\
\hline & & & Sub-base & 16 & 18 & 17 & 19 & 17 & - & - \\
\hline & & & $\mathrm{CA}$ & 6500 & 6500 & 6500 & 6500 & 6500 & - & - \\
\hline & & Módulo & Base & 250 & 330 & 240 & 320 & 350 & - & - \\
\hline & & (MPa) & Sub-base & 180 & 300 & 150 & 200 & 200 & - & - \\
\hline & & & Subleito & 100 & 100 & 90 & 80 & 70 & - & - \\
\hline
\end{tabular}

Na GO-222, a redução no valor do módulo das camadas no segundo ano de avaliação é coerente com os resultados de campo (aumento do valor da deflexão e piora na análise dos defeitos). Desde a primeira 
avaliação, já se supôs que as trincas encontradas poderiam ter como causa o trincamento por retração da base melhorada com cimento. Pode-se verificar que os valores de módulos das camadas de base, subbase e subleito não variaram muito nas G0-215 e GO-147. A maior alteração pode ser observada no módulo do revestimento (adotado como $2000 \mathrm{MPa}$ no primeiro ano de análise). Se o valor do módulo adotado fosse maior, para ajuste da curva gerada com os dados do programa, os valores de módulo das outras camadas seriam menores do que os apresentados na primeira avaliação. Entretanto, houve diferença na espessura das camadas encontradas na segunda avaliação, que foi compensada pela diferença nos valores dos módulos do revestimento, mantendo os valores dos módulos das demais camadas semelhantes.

A Tabela 12 mostra os valores de MR obtidos a partir da realização do ensaio triaxial dinâmico com material de base reciclada coletado durante a obra por Costa (2013) e Silva Junior (2015) e os valores médios dos módulos obtidos em campo para as camadas de base reciclada nos segmentos homogêneos das vias analisadas nos dois anos. Para a base da GO-222, a diferença encontrada no valor dos módulos no primeiro ano de avaliação já foi significativa e, segundo Costa (2013), pode ser explicada pelas reações químicas do material com cimento ocorridas entre a data da coleta das amostras na pista já com cimento e cascalho incorporados e a realização do ensaio em laboratório. Nesse período de espera, as amostras deformadas ficaram condicionadas em sacos plásticos e foram compactadas somente na época de realização do ensaio, não havendo cura após a compactação. Já os ensaios em campo foram realizados logo após a conclusão da obra. Com os valores de módulo encontrados em laboratório e por meio de retroanálises, pode-se inferir que a solução adotada tem potencial para bons resultados. Entretanto, um controle de campo mais cuidadoso deve ser realizado a fim de evitar que as trincas da base se propaguem para o revestimento. Para tanto, pode-se aguardar o aparecimento das trincas na base e tratá-las antes da aplicação do revestimento ou executar uma camada de bloqueio entre a base e o revestimento com tratamento superficial simples ou com geossintético.

Silva Junior (2015) notou a falta de correlação entre os de módulo de campo e de laboratório para a G0-215 e GO-147. 0 autor afirma que o fato das bases recicladas não terem apresentado valores de módulo satisfatórios em campo poderia estar relacionado com a forma de aplicar energias de compactação mais elevadas (como a modificada) ou com algum problema executivo. 0 valor de módulo esperado em laboratório para as bases recicladas seria na ordem de $440 \mathrm{MPa}$. 0 mesmo autor observou que o material da G0-215 apresentou maior quebra dos agregados após a compactação, o que justifica a diferença de valores de módulo obtida em laboratório para o material dessa rodovia e da G0-147. Assim, deve-se verificar a energia de compactação que não gera quebra do material.

Tabela 12: Valores de MR obtidos em laboratório e em campo

\begin{tabular}{|c|c|c|c|c|}
\hline \multirow{2}{*}{$\begin{array}{l}\text { Rodovia } \\
\text { GO-222 }\end{array}$} & \multirow{2}{*}{$\begin{array}{c}\text { Energia de Compactação } \\
\text { Intermodificada }\end{array}$} & \multirow{2}{*}{$\begin{array}{c}\text { MR Laboratório (MPa) } \\
911 \\
\text { (Costa, 2013) }\end{array}$} & \multicolumn{2}{|c|}{ Módulo $_{\text {med }}$ Campo (MPa) } \\
\hline & & & $\begin{array}{c}436 \\
\text { (Costa, 2013) }\end{array}$ & $205^{*}$ \\
\hline GO-215 & Modificada & $\begin{array}{c}214 \\
\text { (Silva Junior, 2015) }\end{array}$ & $\begin{array}{c}264 \\
\text { (Hómez, 2014) }\end{array}$ & $248^{*}$ \\
\hline GO-147 & Modificada & $\begin{array}{c}464 \\
\text { (Silva Junior, 2015) }\end{array}$ & $\begin{array}{c}262 \\
\text { (Rezende, 2014) }\end{array}$ & $298^{*}$ \\
\hline
\end{tabular}

\section{CONCLUSÕES}

Com base neste estudo pode-se concluir que:

- As características das amostras do revestimento não atenderam aos valores determinados por norma, o que ressalta os problemas devido à utilização da dosagem Marshall, principalmente na determinação das densidades e na forma de compactação. Percebeu-se também que a granulometria dos agregados e o tipo de ligante utilizados nas misturas asfálticas geram variações significativas nos valores de RT e MR; 
- As soluções de restauração adotadas demonstraram potencial de utilização, desde que sejam realizados estudos preliminares de tráfego e dos materiais a serem utilizados, a fim de prever seus comportamentos. Ressalta-se, ainda, a importância da execução de um cuidadoso controle tecnológico em campo;

- Apesar das três rodovias terem apresentado comportamentos distintos no monitoramento, a técnica de reciclagem profunda pode ser usada desde que o projeto de restauração considere o mínimo de empirismo e as condições regionais.

\section{AGRADECIMENTOS}

Os autores agradecem à CAPES pelo fornecimento das bolsas de mestrado e à Controladoria Geral do Estado de Goiás pelo apoio financeiro para a realização da pesquisa.

\section{REFERÊNCIAS}

ABNT (2011) NBR 16018: Misturas asfálticas - Determinação da rigidez por compressão diametral sob carga repetida. Associação Brasileira de Normas Técnicas, Rio de Janeiro.

Andriotti, J.L. (2003) Fundamentos de Estatística e Geoestatística. Editora da Universidade do Vale do Rio dos Sinos, São Leopoldo, Rio Grande do Sul.

Aragão, F.T.S; Pazos, A.R.G.; Motta, L M.G.; Kim, Y.R.; Nascimento, L.A.H. (2016) Effects of morphological characteristics of aggregate particles on the mechanical behavior of bituminous paving mixtures. Construction \& Building Materials, v. 123, p. 444-453.

ARRA (2001) Manual Basic Asphalt Recycling. Asphalt Recycling and Reclaiming Association, United States.

ASTM (2003) D 6951: Standard Test Method for Use of the Dynamic Cone Penetrometer in Shallow Pavement Applications. American Society for Testing and Materials, United States.

ASTM (2011) D 2041: standard test method for theoretical maximum specific gravity and density of bituminous paving mixtures. ASTM International, United States.

Bernucci, L.B.; Ceratti, J.A.P.; Motta, L.M.G.; Soares, J.B. (2006) Pavimentação Asfáltica: Formação Básica para Engenheiros (1 ed.). PETROBRAS: ABEDA, Rio de Janeiro, Brasil.

Bessa, I.S.; Aranha, A.L.; Vasconcelos, K.L.; Silva, A.H.M.; Bernucci, L.L.B. (2016) Laboratory and field evaluation of recycled unbound layers with cement for use in asphalt pavement rehabilitation. Materials and Structures, v. 49, p. 2669-2680, 2016. DOI: 10.1617/s11527-015-0675-6.

Bock, A L.; Hartmann, D.; Budny, J.; Specht, L.P.; Ceratti, J.A.P. (2009) Estudo laboratorial sobre os efeitos de diferentes formas de adição de cal a concreto asfáltico. Teoria e Prática na Engenharia Civil, n. 14, p. 56-69.

Chen, X.; Xu, Z. (2009) Effects of Load and Temperature on Permanent Deformation Properties of HMA.Road Pavement Material Characterization and Rehabilitation, ASCE, p. 49-55. DOI: 10.1061/41043(350)7

Choi, Y.T. (2013) Development of a mechanistic prediction model and test protocol for the permanent deformation of asphalt concrete. Dissertation (Doctor of Philosophy). North Carolina State University at Raleigh. Disponível em: <http://www.lib.ncsu.edu/resolver/1840.16/8713>. Acesso em: 18/12/2015.

CNT (2015) Pesquisa CNT de rodovias 2015: relatório gerencial. Confederação Nacional do Transporte. SEST: SENAT. Brasília.

Coelho Jr., M.L.P.; Rocha, P.H.T. (2013) Estudo preliminar de misturas asfálticas à quente utilizadas em obras de pavimentação na região metropolitana de Goiânia. Trabalho de Conclusão de Curso, Universidade Federal de Goiás, Goiânia, Goiás.

Costa, L.C.S. (2013) Avaliação do comportamento de trechos de rodovias restauradas com base reciclada "in situ". Dissertação de Mestrado. Universidade Federal de Goiás, Goiânia, Goiás.

DER-SP (2003) IP-DEP00/003: Avaliação funcional e estrutural de pavimento - Instrução de Projeto. Departamento de Estradas de Rodagem de São Paulo, São Paulo.

DNER (1979) PRO 011: Avaliação Estrutural dos Pavimentos flexíveis - Volume 1 - Procedimento B. Departamento Nacional de Estradas de Rodagem, Rio de Janeiro.

DNER (1994a) ME 117: Mistura betuminosa - determinação da densidade aparente. Departamento Nacional de Estradas de Rodagem, Rio de Janeiro.

DNER (1994b) ME 053: Misturas betuminosas - percentagem de betume. Departamento Nacional de Estradas de Rodagem, Rio de Janeiro.

DNER (1994c) PRO 175: Aferição de viga Benkelman - Procedimento. Departamento Nacional de Estradas de Rodagem, Rio de Janeiro.

DNER (1995) ME 084: Agregado Miúdo - Determinação da densidade real. Departamento Nacional de Estradas de Rodagem, Rio de Janeiro.

DNER (1998a) ME 083: Agregados - análise granulométrica. Departamento Nacional de Estradas de Rodagem, Rio de Janeiro.

DNER (1998b) ME 081: Agregados - Determinação da absorção e da densidade de agregado graúdo. Departamento Nacional de Estradas de Rodagem, Rio de Janeiro.

DNIT (2003a) TER 005: Defeitos nos pavimentos flexíveis e semi-rígidos - Terminologia. Departamento Nacional de Infraestrutura de Transportes, Rio de Janeiro. 
DNIT (2003b) PRO 006: Avaliação objetiva da superfície de pavimentos flexíveis e semi-rígidos - Procedimento. Departamento Nacional de Infraestrutura de Transportes, Rio de Janeiro.

DNIT (2003c) PRO 007: Levantamento para avaliação da condição de superfície de subtrechos homogêneo de rodovias de pavimentos flexíveis e semi-rígidos para gerência de pavimentos e estudos e projetos - Procedimento. Departamento Nacional de Infraestrutura de Transportes, Rio de Janeiro.

DNIT (2006a) ES 031: Pavimentos flexíveis - Concreto asfáltico - Especificação de Serviço. Departamento Nacional de Infraestrutura de Transportes, Rio de Janeiro.

DNIT (2006b) IPR 720: Manual de Restauração de Pavimentos Asfálticos. Departamento Nacional de Infraestrutura de Trans-

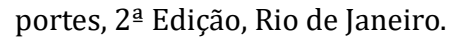

DNIT (2010a) ME 133: Pavimentação asfáltica - Delineamento da linha de influência longitudinal da bacia de deformação por intermédio da Viga Benkelman - Método de ensaio. Departamento Nacional de Infraestrutura de Transportes, Rio de Janeiro.

DNIT (2010b) ME 136: Pavimentação Asfáltica - Misturas Asfálticas - Determinação da resistência à tração por compressão diametral - Método de ensaio. Departamento Nacional de Infraestrutura de Transportes, Rio de Janeiro.

DNIT (2010c) ME 135: Pavimentação Asfáltica - Misturas Asfálticas - Determinação do módulo de resiliência - Método de ensaio. Departamento Nacional de Infraestrutura de Transportes, Rio de Janeiro.

FHWA (1997). Pavement Recycling Guidelines for State and Local Governments - Participant's Reference Book. FHWA-SA-98$042,1997$.

Hómez, J.H.G. (2014) Avaliação de rodovias goianas restauradas com a técnica de reciclagem a frio "in situ”. Dissertação de Mestrado. Universidade Federal de Goiás, Goiânia, Goiás.

Huang, Y.H. (2004) Pavement Analysis and Design (2 $2^{\underline{a}}$ ed). Kentucky: Pearson Education, Inc. Upper Saddle River, New Jersey.

Ibrahim, A. (2007) Performance evaluation of Superpave and Marshall asphalt mix designs to suite Jordan climat and traffic conditions. Construction and Building Materials, n. 21, p. 1732-1740. DOI: 10.1016/j.conbuildmat.2006.05.036

Jaritngam, S.; Somchainuek, O.; Taneerananon, P. (2012) An investigation of lateritic soil cement for sustainable pavements. Indian Journal of Science and Technology, v. 5, n. 11, p 3603-3606.

Lacroix, A.T. (2013) Performance prediction of the NCAT test track pavements using mechanistic models. Dissertation (Doctor of Philosophy). North Carolina State University, NC.

Macêdo, F.N. (2003) Retroanálise de bacias de deflexão reais e teóricas obtidas por métodos estatísticos e dinâmicos. Dissertação de Mestrado. Universidade de Brasília, Brasília, Brasil.

Marques, G.L.O. (2004) Utilização do módulo de resiliência como critério de dosagem de mistura asfáltica: efeito da compactação por impacto e giratória. Tese de doutorado. Universidade Federal do Rio de Janeiro, COPPE, Rio de Janeiro.

Medina, J. Motta, L.M.G. (2015) Mecânica dos Pavimentos (3ae ed.). Interciência, Rio de Janeiro, Brasil.

Morian, D.A.; Solaimanian, M; Scheetz, B.; Jahangirnejad, S. (2012) Developing Standards and Specifications for Full Depth Pavement Reclamation. Technical Report Documentation Page. Report no FHWA-PA-2012-004-090107, Pennsylvania Department of Transportation. Harrisburg, Pennsylvania.

Park, T. (2007) Causes of bleeding in a hot-in-place asphalt pavement. Construction and Building Materials, ASCE, v. 21, p. 2023-2030. DOI: 10.1016/j.conbuildmat.2007.06.008.

Ponte, R.S.; Branco, V.T.F.; Holanda, A.S.; Soares, J.B. (2014) Avaliação de diferentes metodologias para obtenção do Módulo de Resiliência de misturas asfálticas. Transportes, v. 22, n. 2, p. 85-94. DOI: 10.14295/transportes.v22i2.792.

Prowell, B.D.; Brown, E.R. (2007) Superpave mix design: verifying gyration levels in the Ndesign table. National Cooperative Highway Research Program - NCHRP Report 573.Washington, District of Columbia, EUA.

Prudente, C.Q.A. (2015) Estudo laboratorial de misturas asfálticas a quente utilizadas em Goiás. Dissertação de Mestrado. Universidade Federal de Goiás, Goiânia, Goiás.

Ressutte, A.F.B.; Fortes, R.M.; Suzuki, C.Y.; Silva, J.B.R. (2015) Análise da utilização de tela de aço soldada na terceira faixa em rodovia do estado de São Paulo sob jurisdição do DER/SP. In: 9o Congresso Brasileiro de Rodovias e Concessões e 9ª Exposição Internacional de Produtos para Rodovias - BRASVIAS, Brasília.

Rezende, L.R. (2014) Resultados de ensaios de campo na rodovia GO-147. Relatório de pesquisa.

Rosa, F.D.; Jorge, F.S.; Brito, L.A.T.; Ceratti, J.A.P. (2015) Análise do comportamento mecânico de um pavimento reciclado com adição de diferentes agentes estabilizadores. Transportes, v. 23, n. 2, p. 95-104. DOI: 10.14295/transportes.v23i2.880.

Sachet, T. (2007) Controle tecnológico de obras rodoviárias envolvendo a reciclagem In Situ de bases granulares de pavimentos asfálticos. Dissertação de Mestrado. Universidade de Passo Fundo, Passo Fundo, Rio Grande do Sul.

Silva, A.H.M. (2011) Avaliação do Comportamento de pavimentos com camada reciclada de revestimentos asfálticos a frio com emulsão modificada por polímero. Dissertação de Mestrado. Escola Politécnica da Universidade de São Paulo, São Paulo.

Silva Junior, V. M. (2015) Estudo Laboratorial de Bases Granulares Recicladas in situ. Dissertação de Mestrado. Universidade Federal de Goiás, Goiânia, Goiás.

Vasconcelos, K.L. (2004) Comportamento mecânico de misturas asfálticas a quente dosadas pelas metodologias Marshall e Superpave com diferentes granulometrias. Dissertação de Mestrado. Universidade Federal do Ceará, Fortaleza, Ceará. 